\title{
How can 30-60-day ISO move from the South China Sea to Southern China?
}

\author{
Bin Zheng ${ }^{1} \cdot$ Yanyan Huang ${ }^{1} \cdot$ Chunhui Li ${ }^{1} \cdot$ Ailan Lin ${ }^{1}$
}

Received: 16 September 2019 / Accepted: 24 February 2020 / Published online: 4 March 2020

(c) The Author(s) 2020

\begin{abstract}
In the present study, the northward-propagating intraseasonal oscillations (ISOs) over the South China Sea (SCS) during the summer monsoon season are divided into two types. One is the northward propagation of ISOs confined in the SCS (defined as P1-ISO), another for ISOs moving from the SCS to Southern China (SC) defined as P2-ISO. The spatial and temporal structures of the two types of ISOs are compared based on the analysis of the NCEP-NCAR reanalysis datasets. It is found that a significant difference appears in the heat flux anomalies over SC that is attributed to the cloud-radiation effect. A mechanism associated with the changes in the convective instability is proposed to understand the cause of the northward propagation of the ISO from the SCS to SC. For the P1-ISO, a more precipitation over SC leads to a less surface solar radiation and then a cold land surface temperature (LST), which induces an increase of static stability via surface longwave radiation and sensible heat flux. Whereas the total contribution to the convective instability changes does create an unfavorable for ISOs propagating northward, the moisture convergence, mainly controlled by the baroclinic vorticity advection effect, may contribute to an increase of convective instability that favors the ISOs moving northward. For the P2-ISO, a less precipitation over SC results in a more shortwave radiation reaching the ground that induces a warm LST, and thus leading to a warm low-level air temperature and destabilizing the atmosphere ahead of the convection. Moreover, the moisture convergence, dominated by the warm low-level air temperature, also contributes to the increase of convective instability. Thus the convective instability increment should favor the ISOs moving northward. It is worth noting that the baroclinic vorticity advection and moisture advection are not essential for ISOs propagating from the SCS to SC.
\end{abstract}

Keywords Intraseasonal oscillation $\cdot$ Northward propagation $\cdot$ South China Sea summer monsoon $\cdot$ Heat flux

\section{Introduction}

The South China Sea (SCS) summer monsoon (SCSSM) is a subsystem of the Asian monsoon, with unique characteristics that different from those of other Asian monsoon subsystems. The SCSSM has a special geographic location that joins three Asian monsoon subsystems: the subtropical East Asian monsoon, the tropical Indian monsoon, and the western North Pacific (WNP) monsoon (Wang et al. 2009). While the SCSSM rainbelt is linked with that of the WNP summer monsoon (Murakami and Matsumoto 1994; Wang

Bin Zheng

zbin@gd121.cn

1 Institute of Tropical and Marine Meteorology (ITMM), China Meteorological Administration (CMA), and Guangdong Provincial Key Laboratory of Regional Numerical Weather Prediction, Guangzhou 510640, China
1994; Zheng et al. 2013; Zheng and Huang 2019), the circulation characteristics of the SCSSM are similar with those in the tropical Indian monsoon rather than in the WNP monsoon (Zheng et al. 2013; Zheng and Huang 2019). Due to the unique characteristics in geographic location and relation to other monsoon subsystems, the SCSSM has attracted more and more attention.

The SCSSM has prominent climate variability on intraseasonal to geological timescales (Wang et al. 2009). The SCS is one of regions where exhibit the largest intraseasonal variability during boreal summer (Kemball-Cook and Wang 2001; Li et al. 2018). The SCS intraseasonal oscillations (ISOs) usually include two periods of 10-20day and 30-60-day (Mao and Chan 2005; Li et al. 2018; Zheng and Huang 2019), and impact the precipitation over Southern China (SC) with a northward or northwestward movement (Chen et al. 2015; Li et al. 2015; Gao et al. 2016; Zheng and Huang 2018). Moreover, the 
northward-propagating ISOs affect the extreme precipitation (Hsu et al. 2016; Zheng and Huang 2019) and heatwave (Hsu et al. 2017) over East Asia. In comparison to the winter ISO, the boreal summer ISO (BSISO) shows a more complex propagation feature, while the northwardpropagating mode is the most important. The northwardpropagating BSISOs appear in South Asian summer monsoon (Yasunari 1979, 1980; Krishnamurti and Subrahmanyam 1982), the WNP and SCS summer monsoon regions (Murakami and He 1984; Chang et al. 1996; Wang and Xie 1997; Zheng et al. 2011; Zheng and Huang 2018), with a variance equivalent to the sum of the eastward- and westward-propagating modes (Lin et al. 2010). In addition, the eastward-propagating mode occurs most frequently during December through May, while all the independent northward-propagating ISOs occur in boreal summer (Wang and Rui 1990).

Some mechanisms have been proposed to explain the northward propagation of ISO, and the main mechanisms are listed in Table 1. The moisture advection in the planetary boundary layer (PBL) and barotropic vorticity effect are found to be the dominant mechanisms for the northward propagation of ISO (DeMott et al. 2013), which are mainly attributed to the mean state of circulation.

Over the SCSSM region $\left(105^{\circ}-120^{\circ} \mathrm{E}\right)$, a northwardpropagating component of 30-60-day ISOs is evidently found from May to September (Fig. 1). Some northwardpropagating ISOs can reach as far north as around $30^{\circ} \mathrm{N}$, the Yangtze River Basin (marked by red solid lines in Fig. 1), whereas most of the northward-propagating ISOs are confined to the south of $21^{\circ} \mathrm{N}$ (red dashed lines in Fig. 1). Why can some ISOs move from the SCS to SC and others not? Understanding the processes can help us to monitor and forecast the persistent rainfall over SC. As mentioned above, the SCS ISOs usually include two periods of 10-20-day and 30-60-day (Mao and Chan 2005; Li et al. 2018; Zheng and Huang 2019). In this study, we aim to analysis the 30-60day ISOs in the SCSSM region during May to September. The next section describes the datasets and methods used in this study. In Sect. 3, two types of northward-propagating ISOs over the SCS are compared to explore the mechanism of the northward-propagation from SCS to SC, followed by the conclusions from this study.

\section{Data and analysis method}

In this study, the daily three-dimensional winds, water vapor, and air temperature are from the National Centers for Environmental Prediction-National Center for Atmospheric Research (NCEP-NCAR) reanalysis (Kalnay et al. 1996) with $2.5^{\circ} \times 2.5^{\circ}$ grids for the period 1 January 1997 through December 2016. The NCEP-NCAR reanalysis data have 17 pressure levels from 1000 to $10 \mathrm{hPa}$, while the variable of specific humidity is just defined from 1000 to $300 \mathrm{hPa}$. The other datasets for the same period include the daily surface fluxes (surface solar radiation, longwave radiation, latent, and sensible heat fluxes), and sea surface/land skin temperature from NCEP-NCAR with a T62 Gaussian grid and daily precipitation from the Global Precipitation Climatology Project (GPCP) satellite-derived infrared (IR) GOES precipitation index (GPI) daily rainfall estimates at $1^{\circ}$ spatial resolution (Huffman et al. 2001). Note that positive values of latent heat flux, sensible heat flux longwave radiation, and shortwave radiation mean that the energy transfers from the ocean/land to the atmosphere and vice versa for negative values.

The SCS region is $105-120^{\circ} \mathrm{E}, 5.5-20.5^{\circ} \mathrm{N}$, and the $\mathrm{SC}$ region is $105-120^{\circ} \mathrm{E}, 21.5-31.5^{\circ} \mathrm{N}$ in this study. For the convenience, all data are interpolated into $1^{\circ} \times 1^{\circ}$ spatial resolution as the GPI daily precipitation. Moreover, all data except for background fields were filtered by 30-60day bandpass filters. Climatological mean is from 1981 to 2010. The SCSSM longitudes in this study are from $105^{\circ} \mathrm{E}$ to $120^{\circ} \mathrm{E}$. A Hovmöller diagram is introduced to understand the propagation of ISOs. For the northward-propagating ISO confined in the SCS, the latitude and day with ISO reaching the northern boundary (perturbation precipitation maximum equal to $1 \mathrm{~mm}$ day $^{-1}$, varying latitude event by event) were chosen as reference latitude (zero latitude) and reference day (zero day), and the latitude and day with ISO arriving at the mean northern boundary (fixed latitude) were selected

Table 1 Main mechanisms for northward propagation of ISO

Atmospheric internal dynamics

Air-sea (land) interaction
Vertical easterly wind shear (Wang and Xie 1997; Jiang et al. 2004; Drbohlav and Wang 2005)

Baroclinic vorticity advection in the monsoon season (Tsou et al. 2005; Bellon and Sobel 2008)

Barotropic vorticity advection in the pre-monsoon period (Zheng and Huang 2019; Zheng et al. 2019)

Convective momentum transport (Kang et al. 2010; Liu et al. 2015)

Upscale feedback (Zhou and Li 2010; Hsu et al. 2011; Hsu and Li 2011)

Beta shift (Boos and Kuang 2010)

Warm SST related to surface latent heat flux (Kemball-Cook and Wang 2001)

Land surface heat fluxes (Webster 1983) 

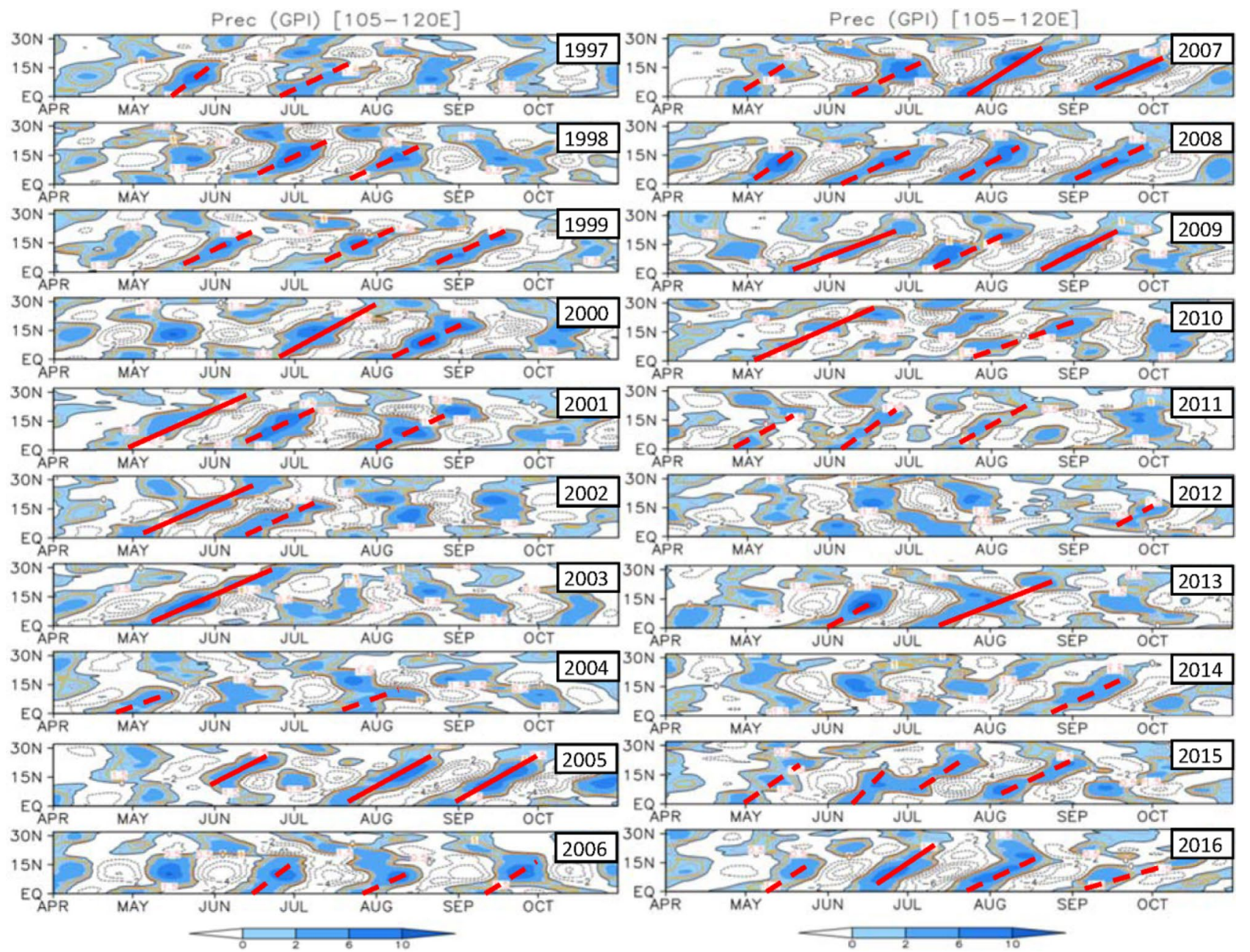

Fig. 1 The 30-60-day-filtered daily precipitation $\left(\mathrm{mm} \mathrm{day}^{-1}\right)$ averaged over the SCSSM region $\left(105^{\circ}-120^{\circ}\right.$ E) for April-October of $1997-2016$. Northward-propagating ISOs reaching around $30^{\circ} \mathrm{N}$ are marked by red solid lines and the rest for red dashed lines

for the northward-propagating ISO that can reach around $30^{\circ} \mathrm{N}$. They cover $10^{\circ} \mathrm{N} / \mathrm{S}$ latitude of the reference latitude and 30 days before and after the reference day. Furthermore, composite analysis, lead-lag correlation, and partial correlation analysis are introduced to understand the processes of the northward-propagating ISOs.

\section{The northward-propagating ISO in the SCSSM region}

\subsection{Two types of ISOs and their structures}

As shown in Fig. 1, there are 14 ISOs that can move from the SCS to SC (27.5\% of the total) and the 37 confined in the SCS (72.5\% of the total), and the former is about $37.8 \%$ of the latter. Noting that we selected the northward-propagating ISO event not only based on visual detection, but also, to a greater extent, based on the location of the precipitation maximum (Figure not shown). If the location of maximum precipitation shows a significant continuous northward shift, the process is selected as a northward-propagating event. Here, the continuous northward shift means that the position of the convection center continues to move northward over time, but without a large latitude jump. Thus, according to the definition of the northern boundary mentioned in Sect. 2 (northernmost position of the precipitation maximum with value larger than $1 \mathrm{~mm} \mathrm{day}^{-1}$ ), we can determine the two types of northward-propagating ISO. Figure 2 shows the composite northward-propagating ISO based on the reference day defined by the ISO precipitation maximum for the all events during May to September. It is indicated that the mean northern boundary (MNB) of the northwardpropagating ISO is around $21.5^{\circ} \mathrm{N}$ by using a threshold of $1.0 \mathrm{~mm} \mathrm{day}^{-1}$. We use the criteria of $1 \mathrm{~mm} \mathrm{day}^{-1}$ because 95\% confidence level threshold related to the location of ISO center is about $1 \mathrm{~mm}$ day $^{-1}$ (Figure not shown). Also we calculated $90 \%$ and $99 \%$ confidence level threshold related 
Fig. 2 Hovmöller diagram of the composite precipitation $\left(\mathrm{mm} \mathrm{day}^{-1}\right)$ over the SCSSM region $\left(105^{\circ}-120^{\circ} \mathrm{E}\right)$ based on the reference day defined by the ISO precipitation maximum for the all events of the northwardpropagating ISO during May to September. Light and dark shadows denote the composites exceed the 95\% and 99\% significant levels, respectively

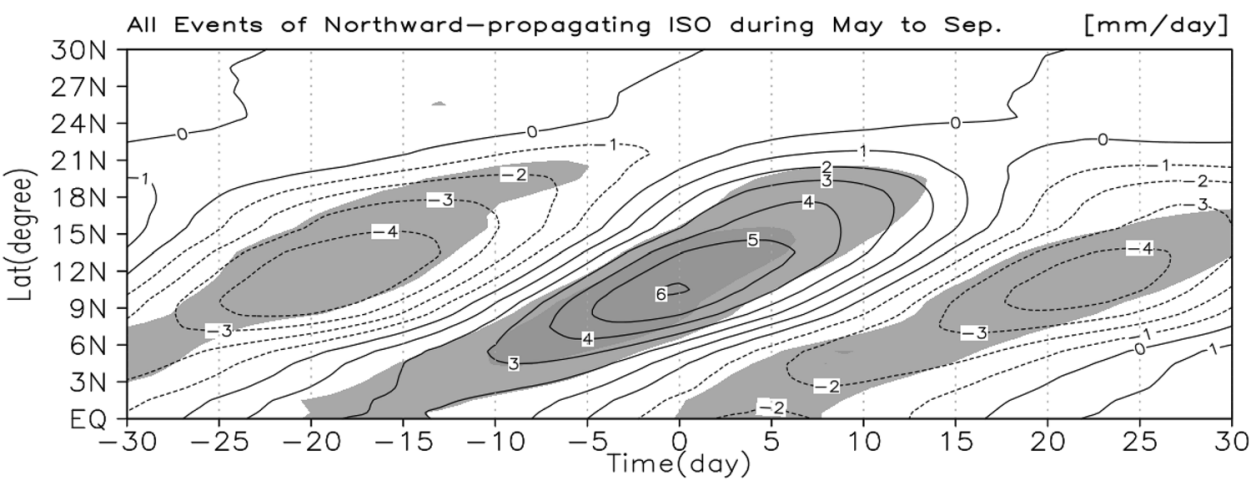

to the location of ISO center, and the results do not show an evident difference (Figure not shown). Besides, we additionally add the contours of $1.5 \mathrm{~mm} \mathrm{day}^{-1}$ and $0.5 \mathrm{~mm} \mathrm{day}^{-1}$ in Fig. 1 with red color, while they are very close to the contour of $1 \mathrm{~mm} \mathrm{day}^{-1}$ and the cases have not changed evidently. It implies that the criteria are not sensitive. Then, we do a composite based on the northern boundary as in Fig. 3. When the northward-propagating ISO is confined to the south of $21^{\circ} \mathrm{N}$ (hereafter P1-ISO), the composite precipitation is based on the day when the anomalous precipitation reaches the real northern boundary of event by event. While the northwardpropagating ISO can reach around $30^{\circ} \mathrm{N}$ (hereafter P2-ISO), the reference day is based on the day when the anomalous precipitation reaches the $\mathrm{MNB}\left(21.5^{\circ} \mathrm{N}\right)$. Figure 3a shows the P1-ISO with a northern boundary of $20.5^{\circ} \mathrm{N}$ nearly same to that of all events in Fig. 2 and the P2-ISO in Fig. $3 \mathrm{~b}$ has a northern boundary about $27.5^{\circ} \mathrm{N}$ by using a threshold of $1.0 \mathrm{~mm}$ day $^{-1}$.

It is worth understanding why some ISOs can move to the farther north and others cannot. Since the mean state of the atmospheric circulation controls the northwardpropagating ISOs as mentioned above, we first examine the climatological background fields in the SCSSM region (Fig. 4). From Fig. 4a, one can see that the mean boundary of 30-60-day northward-propagating ISO is indeed around $21^{\circ} \mathrm{N}$. Corresponding mean states of background fields are shown in Fig. 4b-f. It can be found that the vorticity advection about baroclinic mean meridional wind (Fig. 4c), and moisture advection about low-level meridional wind (Fig. 4e) can do their work on the northwardpropagating ISO not only in the SCS but in SC. While the effects of vertical easterly wind shear (Fig. 4b), atmospheric convective instability (Fig. 4d), and moisture advection related to low-level humidity (Fig. 4f) are confined to the south of $21^{\circ} \mathrm{N}$. Following Zhang et al. (2004) and Ding and He (2006), the convective instability in this study is defined as the difference of equivalent potential temperature $\left(\theta_{e}\right)$ between the middle and surface-lower troposphere:
Fig. 3 Same as Fig. 2, but for the northward-propagating ISOs a confined to the south of $21^{\circ}$ $\mathrm{N}$, and $\mathbf{b}$ reaching around $30^{\circ}$ $\mathrm{N}$. The zero day of $\mathrm{x}$-axis in $\mathbf{a}$ is the day when ISO arrives in the northern boundary and that in $\mathbf{b}$ for ISO reaching the mean northern boundary (about $21.5^{\circ} \mathrm{N}$ ) in Fig. 2 (a) P1: Northward-propagating ISO confined to the south of $21^{\circ} \mathrm{N}$

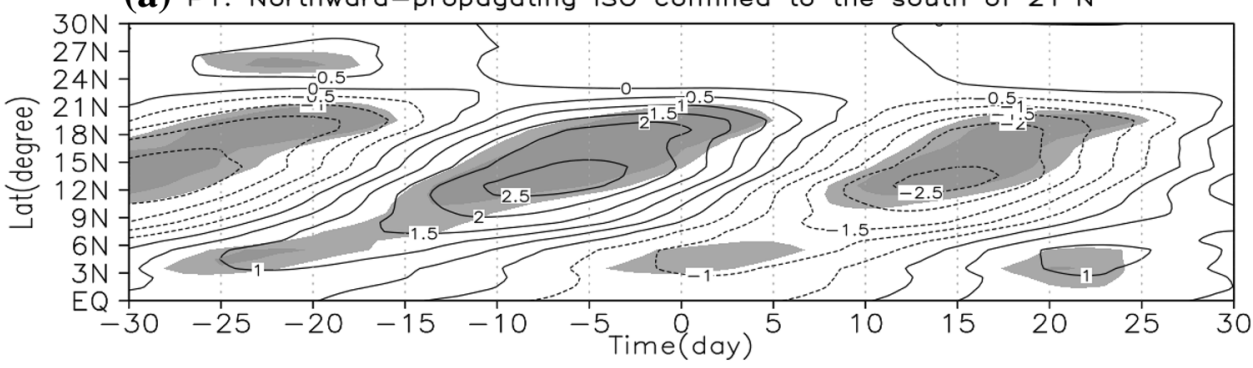

(b) P2: Northward-propagating ISO reaching around $30^{\circ} \mathrm{N}$

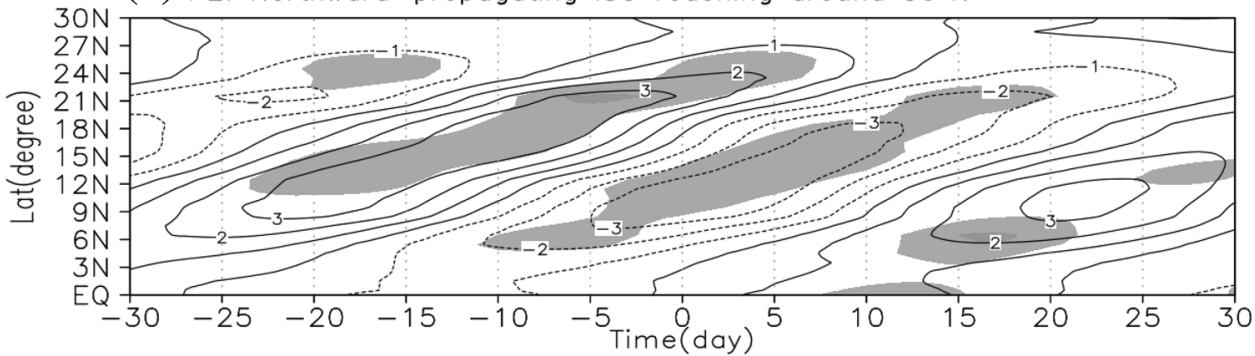


Fig. 4 Mean state over the SCS $\left(105^{\circ}-120^{\circ} \mathrm{E}\right)$ : a precipitation as ISOs reach the northern boundary $\left(\mathrm{mm}\right.$ day $^{-1}$, northern boundary defined as the northernmost location of $1 \mathrm{~mm}$ day $^{-1}$ perturbation precipitation), $\mathbf{b}$ vertical wind shear (200-850hPa zonal winds; $\left.\mathrm{m} \mathrm{s}^{-1}\right)$, c differences of meridional winds between 200 and $850 \mathrm{hPa}(200$ $\left.850 \mathrm{hPa} ; \mathrm{m} \mathrm{s}^{-1}\right)$, d differences of equivalent potential temperature $\left(\theta_{e}\right)$ between the middle and surface-lower troposphere $\left(\mathrm{K},\left.\theta_{e}\right|_{600-300 \mathrm{hPa}}-\left.\theta_{e}\right|_{\mathrm{sfc}-700 \mathrm{PPa}}\right)$, e surface-lower tropospheric meridional wind $\left(\mathrm{m} \mathrm{s}^{-1}\right)$, and f surface-lower tropospheric specific humidity $\left(\mathrm{g} \mathrm{Kg}^{-1}\right)$ (a) PREC $[\mathrm{mm} /$ day $]$

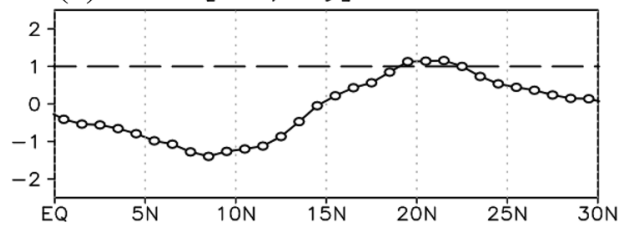

(b) $4200-4850[\mathrm{~m} / \mathrm{s}]$

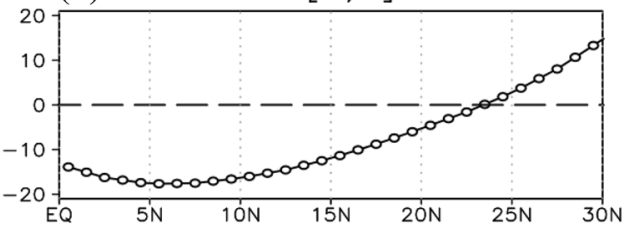

(d) $\theta(600-300)-\theta(\mathrm{sfc}-700)[\mathrm{K}]$
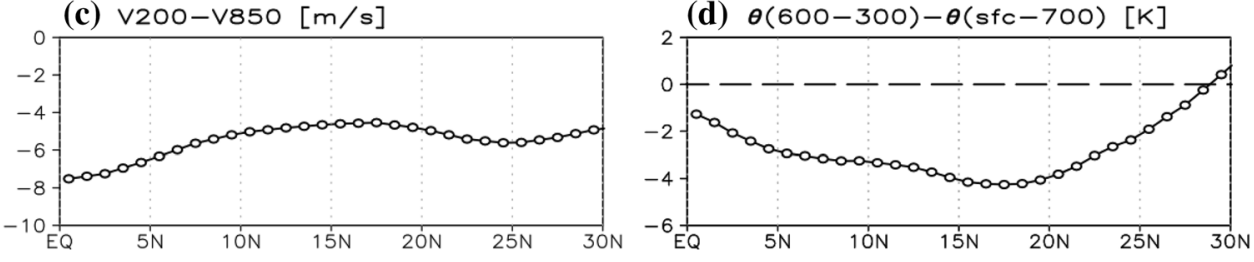

(e) $V_{\text {toto-700 }}[\mathrm{m} / \mathrm{s}]$

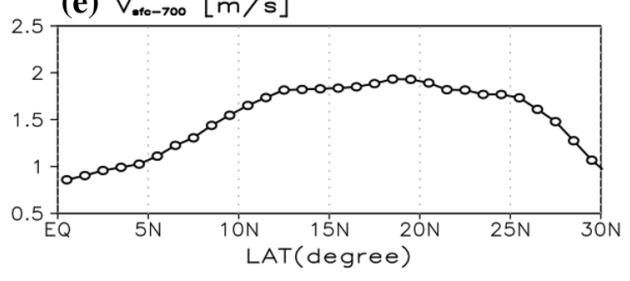

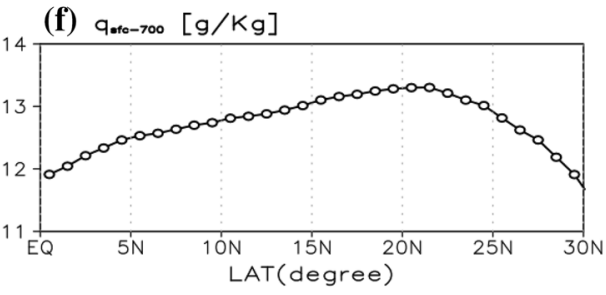

$\Delta \theta_{e}=\left.\theta_{e}\right|_{600-300 \mathrm{hPa}}-\left.\theta_{e}\right|_{\mathrm{sfc}-700 \mathrm{hPa}}$

A negative value of $\Delta \theta_{e}$ implies that the atmosphere is potentially unstable. From Fig. 4d, one can infer that the atmosphere favors the development of convection both in the SCS and in SC, especially between $15-20^{\circ} \mathrm{N}$.

Next, we take a composite approach to reveal the meridional and vertical structure of two types of the northwardpropagating ISOs. Figure $5 \mathrm{a}-\mathrm{c}$ shows the meridionalvertical structure of the composite P1-ISO (marked by red dashed lines in Fig. 1) and Fig. 5d-f for the P2-ISO (marked by red solid lines in Fig. 1). It is indicated that a positive vorticity center with an equivalent barotropic structure leads the convection by around $1-2^{\circ}$ both for the P1-ISO (Fig. 5a) and the P2-ISO (Fig. 5d). This barotropic vorticity is associated with the baroclinic mean meridional wind (Fig. 4c) rather than the vertical easterly wind shear (Fig. 4b), since the former has a greater contribution to the vorticity tendency (With $5.06 \times 10^{-6} \mathrm{~s}^{-1}$ day $^{-1}$ of maximum value north of the convection center for the P1-ISO and $8.38 \times 10^{-6} \mathrm{~s}^{-1}$ day $^{-1}$ for the P2-ISO, Figure not shown) than the latter (With $4.67 \times 10^{-7} \mathrm{~s}^{-1}$ day $^{-1}$ of maximum vorticity tendency north of the convection center for the P1-ISO and $3.21 \times 10^{-7} \mathrm{~s}^{-1}$ day $^{-1}$ for the P2-ISO, Figure not shown). Figure $5 \mathrm{~b}$ and $\mathrm{c}$ show that the low-level convergence and moisture have similar pattern to the barotropic vorticity, implying that the free atmosphere barotropic vorticity would induce convergence in the PBL, and then lead to a moisture convergence. Noting that the center of the former two is closer to the convection than that of the vorticity, the convergence is suppressed in the north of the convection. Different from the
P1-ISO, more remarkable meridional asymmetries appear in the low-level convergence and moisture of the P2-ISO. It is implied that the convergence to the north of the convection is enhanced for the P2-ISO. Although the moisture advection by the mean meridional wind in the lower troposphere (Fig. 4e) also can lead to a northward shift of the moisture convergence, it is much less than the contribution of the PBL moisture convergence (Figure not shown).

\subsection{The effects of surface heat flux}

Warm underlying surface temperature anomalies usually transfer the energy from the underlying surface to atmosphere, and then the destabilized atmosphere would induce low-level convergence. Thus, Kemball-Cook and Wang (2001) and Hsu et al. (2004) proposed a mechanism associated with sea surface heat flux to explain the northwardpropagating ISO over the ocean region. Though observations show that the strongest northward-propagating ISO appears over the SCS (Fig. 1), the purpose of this study is to understand the processes of northward-propagating ISO from the SCS to SC. Therefore, we pay more attention to the land surface heat flux. Webster (1983) hypothesized that the land surface heat flux may play a role in leading to a northward shift of the convection, while the effect of solar radiation, considered in this study, is ignored.

Figure 6 shows the Hovmöller diagrams of the surface heat flux anomalies for the P1-ISO. According to the definition of the reference latitude, we know lat 1-10 in Fig. 6 denote land of SC and lat - 10-0 for the north of the SCS. From Fig. 6a, we can see that cold land surface temperature 
(a) P 1: vorticity

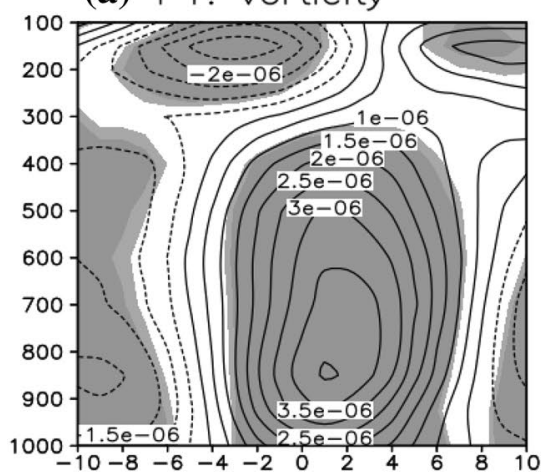

(d) P2: vorticity

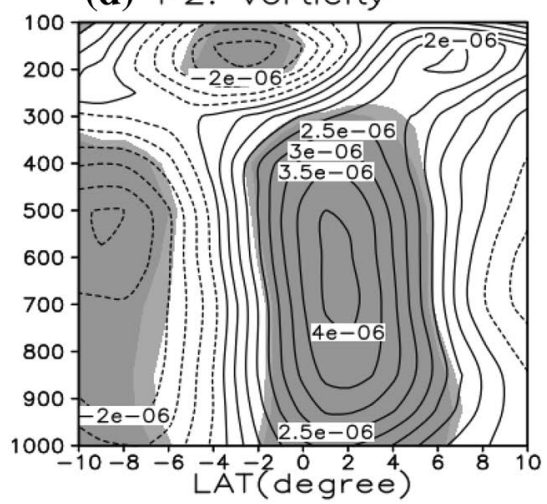

(b) P1: divergence

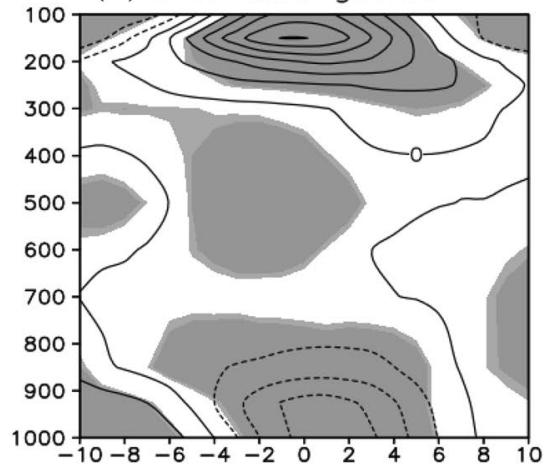

(e) P2: divergence

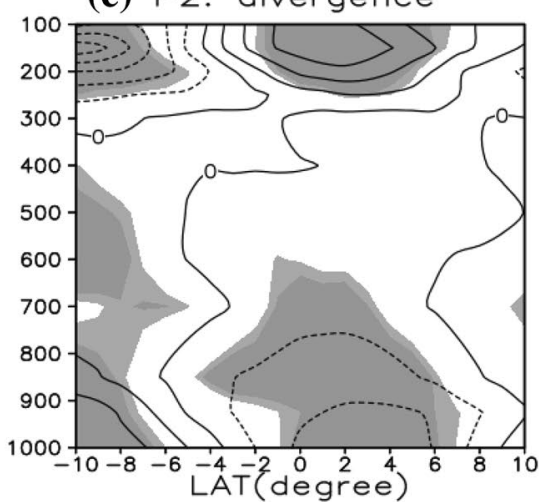

(c) P1: specific humidity

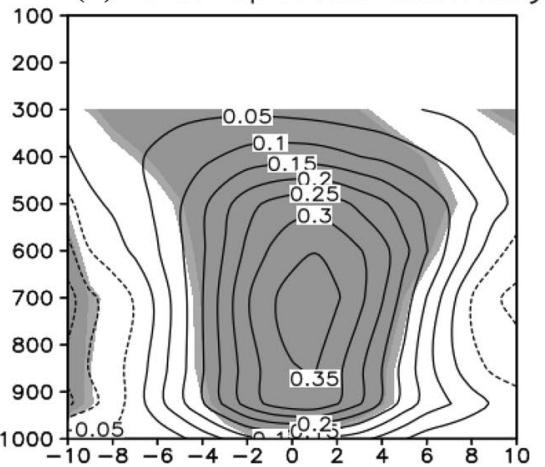

(f) P2: specific humidity

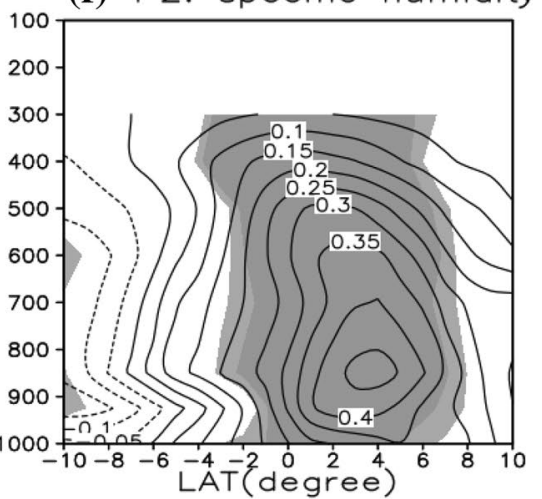

Fig. 5 Meridional-vertical structures of the northward-propagating ISOs over the SCS based on the reference latitude and reference day relative to two types of the northward-propagating ISOs as shown in Fig. 3: a-c is the fields of vorticity $\left(\mathrm{s}^{-1}\right)$, divergence $\left(\mathrm{s}^{-1}\right)$, and specific humidity $\left(\mathrm{g} \mathrm{Kg}^{-1}\right)$ respectively in the P1-ISO; $\mathbf{d}-\mathbf{f}$ are same as

(LST) anomalies (LSTAs) appear in entire SC during day -10 to day -5 . Moreover, negative LSTAs, with a minimum value at around day 0 , are maintained from day -4 through day 15 in the south of SC. Cold LSTAs cool the lowlevel air temperature via reducing heat flux from the ground to the atmosphere (e.g. surface sensible heat flux as shown in Fig. 6f, surface longwave radiation in Fig. 6g, or the sum of the two in Fig. 6h). This suggests that the cold LSTAs may lead to an increase of static stability, which depresses the low-level convergence over SC. Thus the low-level convergence center and caused perturbation moisture maximum for the P1-ISO appears at around the convection center (as shown in Fig. $5 \mathrm{~b}$ and c, and the position of the convection center here is coincident with the northern boundary according the definition). Obviously, that is not a favorable condition for ISOs moving northward.

As to the factor which affects the LST changes, we examine the relationship between the perturbations of surface latent heat flux and solar radiation and the LSTA tendency. From Fig. $6 \mathrm{~b}$ and e, it can be seen that the pattern of sum of the former two is similar to that of LSTA tendency. This a-c but for the P2-ISO. The positive (negative) value of $x$ axis means the distance to the north (south) of the reference latitude. The two shaded areas indicate the composite anomalies exceeding $90 \%$ and $95 \%$ confidence levels

implies that the LST changes are controlled by both the solar radiation and the surface latent heat flux. Comparing Fig. 6c and $d$, we can find that the surface shortwave radiation should play a more important role in affecting the LSTAs than the surface latent heat flux in SC, while in the SCS, the opposite is true. Moreover, from Fig. $6 \mathrm{~b}$ and c, we can find the precipitation anomaly is in phase with the change in the LSTA and surface shortwave radiation. That implies that the latter two may be caused by the ISO precipitation.

Figure 7 is same as Fig. 6 but for the P2-ISO. From Fig. $7 \mathrm{a}$, one can see that warm LSTAs appear in the entire $\mathrm{SC}$ region at and before day 0 when the ISO reaches the $\mathrm{MNB}$, and change to a cold condition after then. Therefore, at day 0 , the atmosphere tends to be unstable over SC, leading to a farther northward shift of the low-level convergence center and induced specific humidity maximum. Comparing Fig. 7f-h, we can find that surface longwave radiation should have a larger contribution to the tendency of low-level air temperature than surface sensible heat flux. Different from the P1-ISO, the LST changes in SC (Fig. 7b) are controlled by surface solar radiation (Fig. 7c), not surface latent heat 

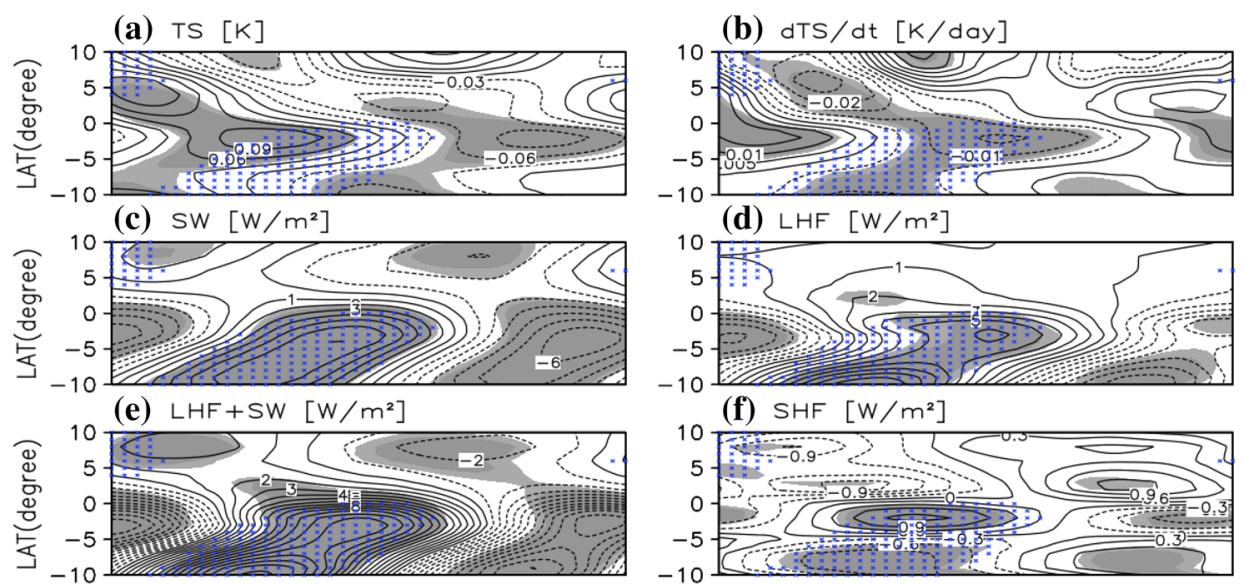

(g) $\mathrm{LW}\left[\mathrm{W} / \mathrm{m}^{2}\right]$
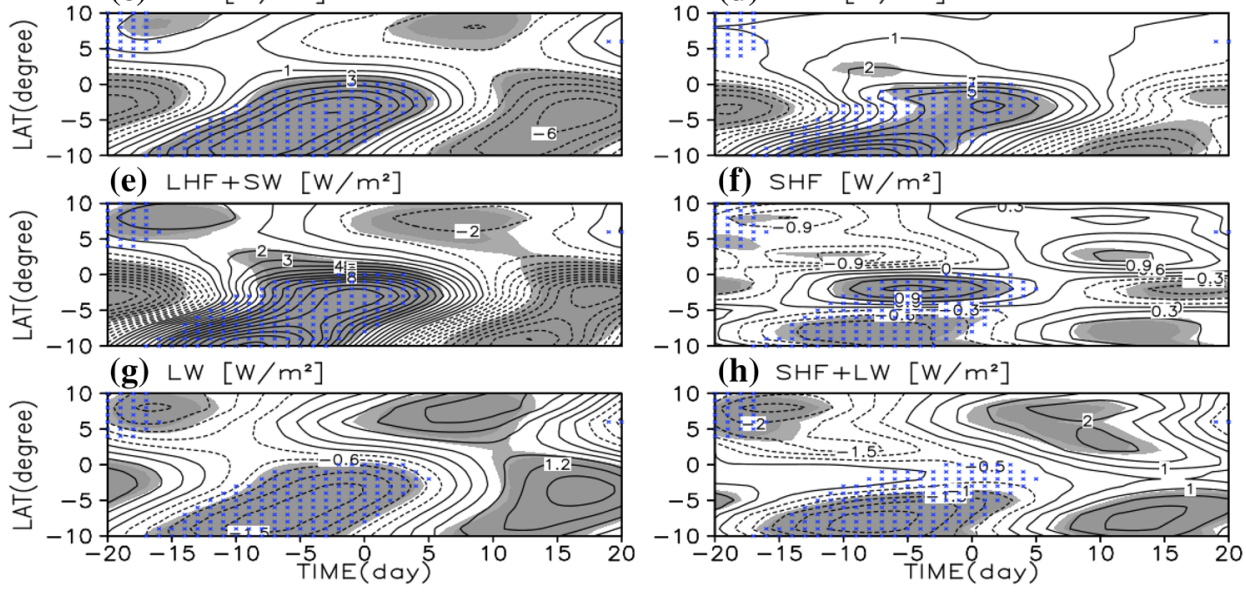

Fig. 6 Composites of the northward-propagating ISOs over the SCS based on the reference latitude and reference day relative to the P1-ISO. a Land/sea surface temperature (K), b land/sea surface temperature tendency $\left(\mathrm{K} \mathrm{day}^{-1}\right)$, $\mathbf{c}$ surface solar radiation $\left(\mathrm{W} \mathrm{m}^{-2}\right), \mathbf{d}$ surface latent heat flux $\left(\mathrm{W} \mathrm{m}^{-2}\right)$, e surface solar radiation plus latent heat flux $\left(\mathrm{W} \mathrm{m}^{-2}\right)$, $\mathbf{f}$ surface sensible heat flux $\left(\mathrm{W} \mathrm{m}^{-2}\right)$, g surface upward longwave radiation $\left(\mathrm{W} \mathrm{m}^{-2}\right)$, and $\mathbf{h}$ surface sensible heat flux

plus upward longwave radiation $\left(\mathrm{W} \mathrm{m}^{-2}\right)$. The positive (negative) value of the $x$ axis means the day after (before) the reference day. The anomalous precipitation composite exceeding 90\% confidence level is displayed with blue cross. The light and dark gray areas indicate the composite anomalies exceeding 90\% and 95\% confidence levels, respectively

Fig. 7 As in Fig. 6, but for the P2-ISO (a) $\mathrm{TS}[\mathrm{K}]$

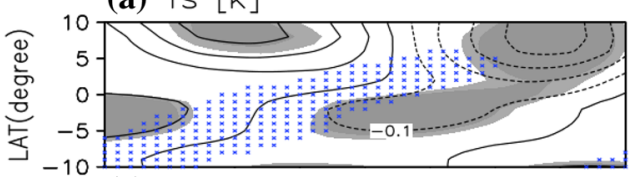

(c) $\mathrm{sW}\left[\mathrm{W} / \mathrm{m}^{2}\right]$

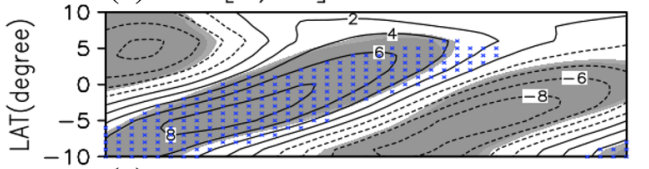

(e) $L H F+S W\left[W / m^{2}\right]$

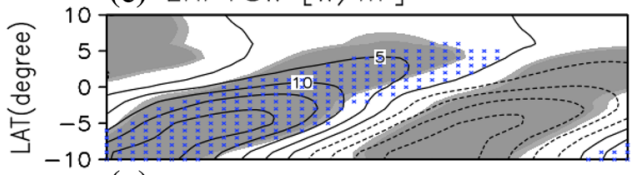

(g) $L W\left[W / \mathrm{m}^{2}\right]$

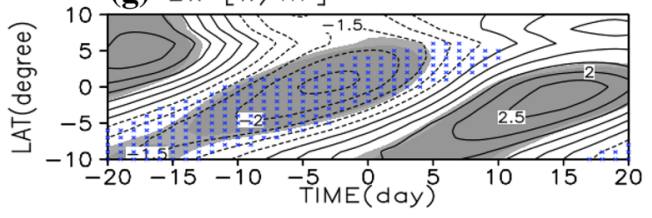

(b) $d T S / d t[K / d a y]$

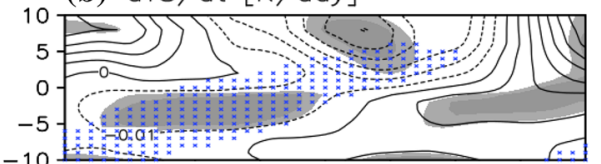

(d) $\operatorname{LHF}\left[\mathrm{W} / \mathrm{m}^{2}\right]$

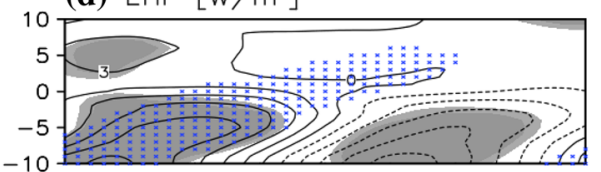

(f) $\mathrm{SHF}\left[\mathrm{W} / \mathrm{m}^{2}\right]$

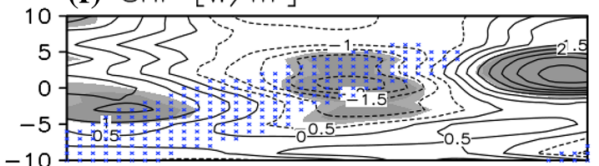

(h) $\mathrm{SHF}+\mathrm{LW}\left[\mathrm{W} / \mathrm{m}^{2}\right]$

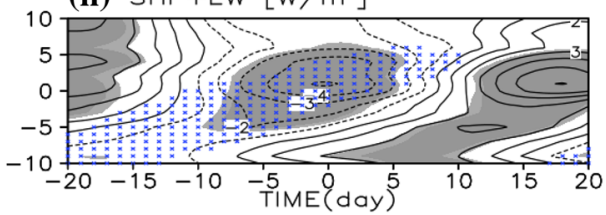

flux (Fig. 7d). But in the SCS, the LST changes are dominated by both of them, with a relatively greater contribution of surface latent heat flux (Fig. 7c-e), which is similar to the P1-ISO. On the other hand, there is a relative large LST anomaly leading the precipitation anomaly in SC, implying that the LST anomaly should play an important role in the northward propagation of ISO from the SCS to SC.

As mentioned above, for the P1-ISO (P2-ISO), cold (warm) LST in SC should have a negative (positive) contribution to ISOs propagating farther northward via depressed 
(enhanced) low-level convergence. While the LST changes in SC are dominated by the surface shortwave radiation, not the surface latent heat flux. From Fig. 3, we can see that a positive (negative) phase in the ISO precipitation appears before the convection has moved to SC for the P1-ISO (P2-ISO). Since perturbation precipitation would induce the changes in surface solar radiation, it may be a key factor in affecting the ISOs propagating farther northward, e.g. from the SCS to SC.

To reveal the effect of the SC precipitation, we conduct a lead-lag correlation analysis to examine the relationship between the ISO perturbations and the precipitation over SC (Fig. 8). Figure 8a shows that the precipitation over SC and that at the reference latitude (lat 0), for the P1-ISO, have a main negative correlation during day 0 -day 10 of lag-time. That implies that the convection is confined to the south of lat 0 (about $20.5^{\circ} \mathrm{N}$ ), that is to say, the ISOs cannot propagate from the SCS to SC. While the precipitation over SC leads the ISO about 20 days, which is consistent with what Fig. 3a shows. As a result, the surface solar radiation maximum can be found around 6 days after the precipitation maximum (Fig. 8b). Then the positive (upward) solar radiation leads to a cold surface air temperature about 5 days after (Fig. 8c), and the latter would induce a divergence (Fig. 8d) that prevents the development and northward propagation of convection.

For the P2-ISO, different processes occur over SC. Figure $8 \mathrm{e}$ shows that the rainy phase of the $\mathrm{SC}$ precipitation lags that at zero latitude about 6 days, implying about 6 days for the ISO to propagate from the SCS to SC, which is consistent with what Fig. $3 b$ shows. Moreover, the surface solar radiation and the precipitation over $\mathrm{SC}$ are almost in phase (Fig. 8f), which is consistent with that of the northwardpropagating ISOs (e.g. Zheng and Huang 2019), but different from that of the P1-ISO (Fig. 8b). A main negative solar radiation (downward flux), ahead of the precipitation maximum (Fig. 8f), heats the surface air temperature (Fig. 8g), and then causes a PBL convergence (Fig. 8h) and thus a northward shift of the convection.

\subsection{Role of anomalous convective instability}

The background convective instability, with a negative meridional gradient, would create a favorable condition for ISOs moving northward because of the destabilized Rossby waves ( $\mathrm{Li}$ et al. 2013). While the background convective instability, with a positive meridional gradient north of about $17.5^{\circ} \mathrm{N}$ (as shown in Fig. 4d), has a negative contribution to the northward propagation of ISOs over SC. Rather than the background convective instability, anomalous convective instability north of the convection center is essential to drive ISOs northward. As shown in Fig. 9a, the positive convective instability parameter (defined as an averaged value of $\Delta \theta_{e}$ over SC) appears in the P1-ISO at day 0 (a reference day) and several days before, while it is opposite for the P2-ISO. What are the relative contributions of the low-level (surface-700 hPa) and mid-level (600-300 hPa) $\theta_{e}$ to cause the anomalous convective instability over SC? From Fig. 9b, one can see that $\Delta \theta_{e}$ over SC is mainly attributed to the lowlevel $\theta_{e}$ for both the P1-ISO and P2-ISO.

As $\theta_{e}$ is determined by specific humidity $(q)$ and air temperature $(T)$, what are their relative roles in causing
Fig. 8 Lead-lag correlation of the P1-ISO perturbations in SC between a precipitation and that at zero latitude (a reference latitude), b surface solar radiation and precipitation, $\mathbf{c}$ surface air temperature and surface solar radiation, and $\mathbf{d}$ low-level divergence (1000-700 hPa) and surface air temperature. $\mathbf{e}-\mathbf{h}$ are same as $\mathbf{a}-\mathbf{d}$, but for the P2-ISO. Dashed lines indicate the significance test with $95 \%$ confidence level (a) P1-ISO: Lag-Cor[PR $\left[R_{s c}, P R_{\text {lato }}\right]$

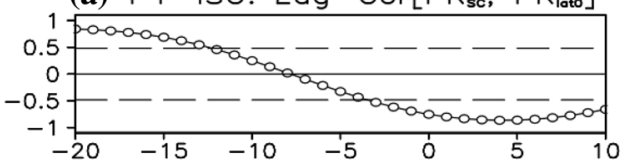

(b) $\mathrm{P}$ 1-ISO: $\mathrm{Lag}-\operatorname{Cor}\left[\mathrm{SW}_{\mathrm{sc}}, \mathrm{PR}_{\mathrm{sc}}\right]$

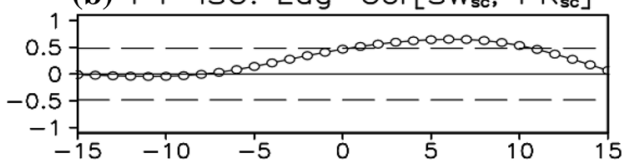

(c) P1-ISO: $L a g-\operatorname{Cor}\left[\mathrm{TS}_{\mathrm{sc}}, \mathrm{SW}_{\mathrm{sc}}\right]$

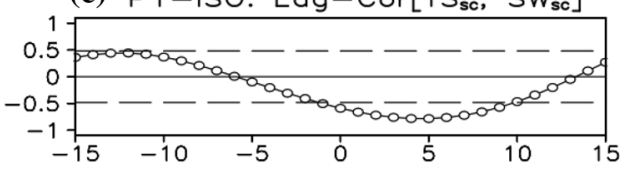

(d) P1-ISO: Lag-Cor[DIV $\left.\mathrm{sc}_{\mathrm{sc}}, \mathrm{TS}_{\mathrm{sc}}\right]$

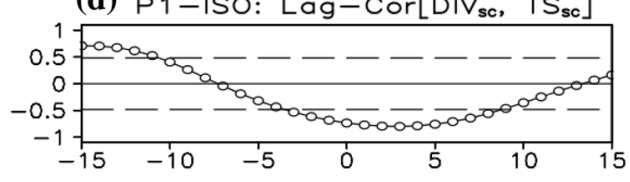

(e) $P 2-I S O: L a g-C o r\left[P R_{s c}, P R_{\text {lato }}\right]$

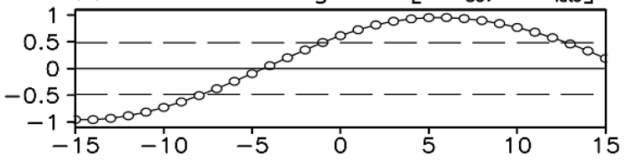

(f) $\mathrm{P} 2-I \mathrm{SO}: \mathrm{Lag}-\mathrm{Cor}\left[\mathrm{SW}_{\mathrm{sc}}, \mathrm{PR}_{\mathrm{sc}}\right]$

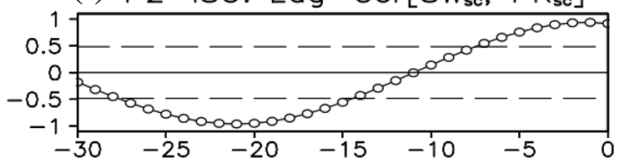

(g) P2-ISO: $\mathrm{Lag}-\operatorname{Cor}\left[\mathrm{TS}_{\mathrm{sc}}, \mathrm{SW}_{\mathrm{sc}}\right]$

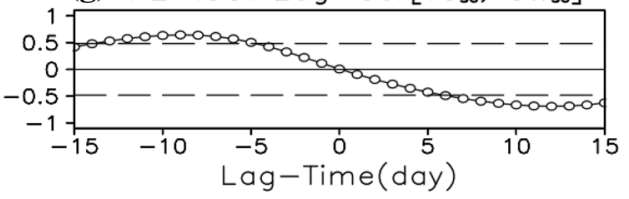

(h) P2-ISO: $\mathrm{Lag}-\operatorname{Cor}\left[\mathrm{DIV}_{\mathrm{sc}}, \mathrm{TS}_{\mathrm{sc}}\right]$

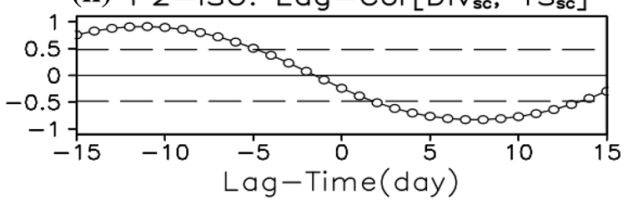


Fig. 9 a Convective instability (K) over SC $\left(105^{\circ}-120^{\circ} \mathrm{E}\right.$ and $\left.22.5^{\circ}-31.5^{\circ} \mathrm{N}\right)$, and $\mathbf{b}$ the mean convective instability (denoted by $\Delta \theta_{e}{ }^{\prime}, \mathrm{K}$ ) and relative contribution from the lower level (surface-700 $\mathrm{hPa}, \mathrm{K}$ ) and the upper level (600-300 hPa, K) from day -10 to day 0 . The solid line and dark colored bar represent the P1-ISO, and the open circle line and light colored bar for the P2-ISO. The positive (negative) value of the $x$ axis in a means the day after (before) the reference day
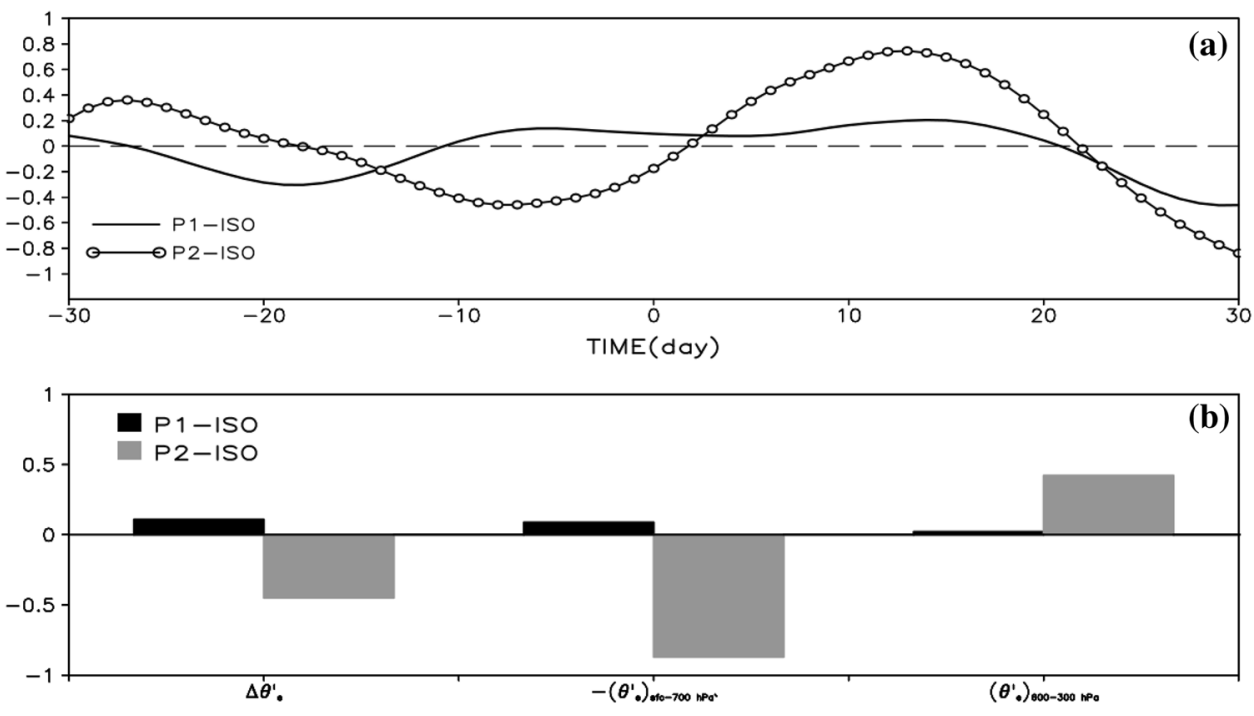

the $\Delta \theta_{e}$ anomalies $\left(\Delta \theta_{e}{ }^{\prime}\right)$ over SC? To address this question, we calculate the correlation coefficients between $\Delta \theta_{e}$ and either $q$ or $T$ (as shown in Fig. 10). Figure 10 shows that the $\Delta \theta_{e}{ }^{\prime}$ over SC has close relationship with both $q^{\prime}$ (low-level specific humidity anomaly) and $T^{\prime}$ (low-level air temperature anomaly) at lower level by the normal correlation calculations, whereas the $T^{\prime}$ may contribute to the $q^{\prime}$ as mentioned above. Therefore we introduce a partial correlation analysis to explore the partial contribution from the variation $q^{\prime}$ or $T^{\prime}$. In Fig. 10, the partial correlation of $\left[\Delta \theta_{e}{ }^{\prime}, q^{\prime}\left(T^{\prime}\right)\right]$ reflects the relationship between the $\Delta \theta_{e}{ }^{\prime}$ and $q^{\prime}\left(T^{\prime}\right)$ excluding the contribution from $T^{\prime}\left(q^{\prime}\right)$ -induced $q^{\prime}\left(T^{\prime}\right)$. For the P1-ISO, the results from the normal and partial correlation are similar, implying that the $q^{\prime}$ or $T^{\prime}$ have a relatively independent contribution to the $\Delta \theta_{e}{ }^{\prime}$. While the partial correlation of $\left[\Delta \theta_{e}{ }^{\prime}, T^{\prime}\right]$ is smaller than that from the normal correlation in the P2-ISO, this implies that the $q^{\prime}$ has a positive contribution to the relationship between the $\Delta \theta_{e}{ }^{\prime}$ and $T^{\prime}$. Moreover, the partial correlation of $\left[\Delta \theta_{e}{ }^{\prime}, q^{\prime}\right]$ is not significant that is different from the result from the normal correlation. Thus it may be concluded that the change in specific humidity over SC is greatly attributed to the $T^{\prime}$ for the P2-ISO.

The correlation coefficient analysis (including the partial correlation) can only present the linear correlation between the two fields, while the instability must be induced by nonlinear interaction between temperature and moisture. Therefore, we did some tests to compare the quantitative contributions of temperature and moisture to the changes in convective instability following Zhao et al. (2013). First, we kept the specific humidity constant while allowing the temperature to change realistically on the intraseasonal time scale (bar labeled due to $T^{\prime}$ as shown in Fig. 11). Second, we kept the temperature constant while allowing the humidity to vary (bar labeled due to $q^{\prime}$ as shown in Fig. 11). For the P1-ISO, almost all the lower $\theta_{e}$ change is attributed to $T^{\prime}$ (Fig. 11a). While $q^{\prime}$ change contributes to about $60 \%$ of the lower $\theta_{e}$ change for the P2-ISO, the increase of $T^{\prime}$ also plays a role (Fig. 11b). Moreover, $q^{\prime}$ change includes the $T^{\prime}$ -induced moisture convergence, and $T^{\prime}$ change includes the $q^{\prime}$-induced change in air temperature due to heat and radiative flux anomalies. Thus the net contribution of $q^{\prime}$ to $\Delta \theta_{e}{ }^{\prime}$

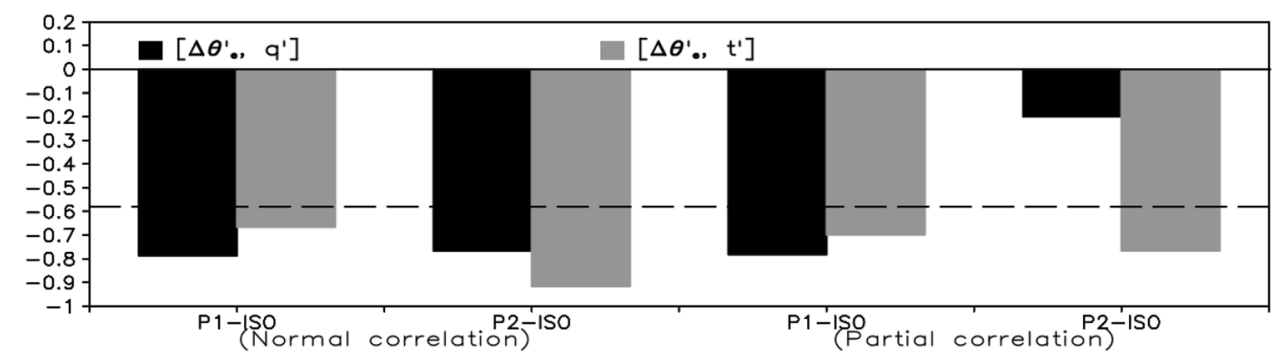

Fig. 10 Correlation coefficients averaged over SC. The dark colored bar represent the correlation between the $\Delta \theta_{e}{ }^{\prime}$ and $q^{\prime}$, and the light colored bar for that of $\Delta \theta_{e}{ }^{\prime}$ and $T^{\prime}$. In this study, the partial corre- lation of $\left[\Delta \theta_{e}{ }^{\prime}, q^{\prime}\left(T^{\prime}\right)\right]$ reflects the relationship between the $\Delta \theta_{e}{ }^{\prime}$ and $q^{\prime}\left(T^{\prime}\right)$ excluding the contribution from $T^{\prime}\left(q^{\prime}\right)$-induced $q^{\prime}\left(T^{\prime}\right)$ 
Fig. 11 Change of the $-\theta_{e \mathrm{~L}}(\mathrm{~K})$ from day $(-10-0)$ to day $(-50$ to -40$)$ and contributions to the $-\theta_{e \mathrm{~L}}$ change due to lowertropospheric $q^{\prime}, T^{\prime}, q^{*}$ and $T^{*} \cdot q^{\prime}$ denotes ISO specific humidity, and $T^{\prime}$ for ISO air temperature. $q^{*}$ effects include the contributions from $q^{\prime}$ minus regression of $q$ onto $T^{\prime}$ and from regression of $T$ onto $q^{\prime}$, and $T^{*}$ effects for the contributions from $T^{\prime}$ minus regression of $T$ onto $q^{\prime}$ and from regression of $q$ onto $T^{\prime}$ (a) $\mathrm{P} 1-1 \mathrm{SO}$

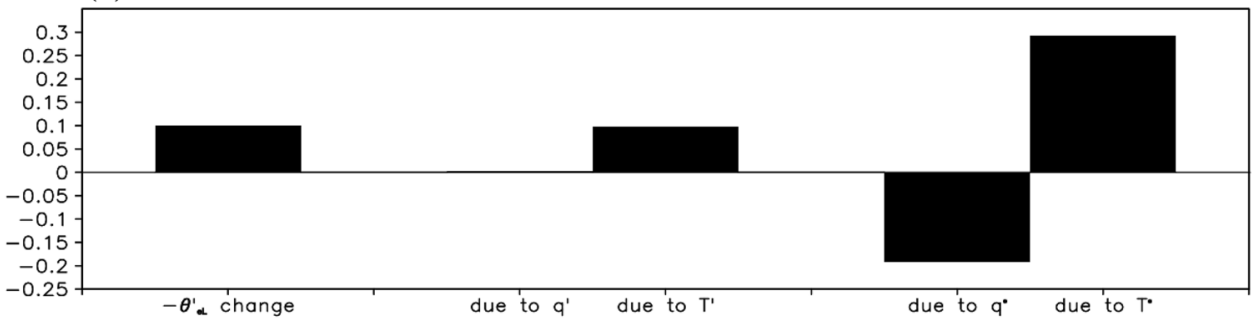

(b) $\mathrm{P} 2-1 \mathrm{SO}$

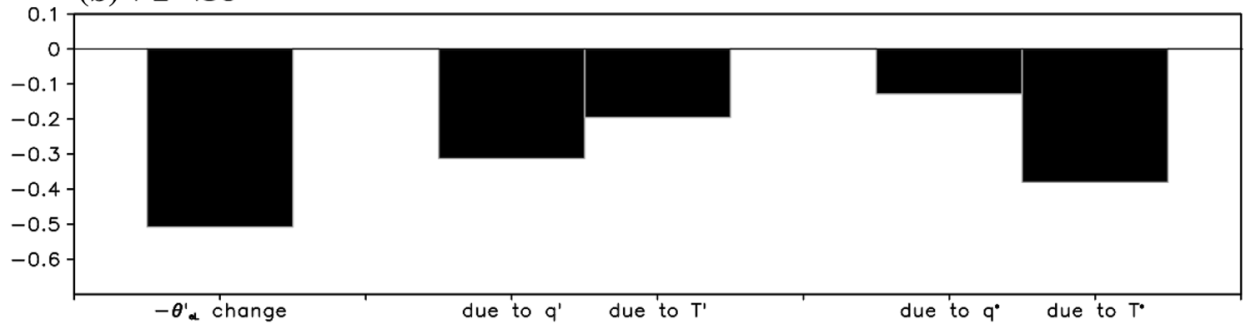

can be calculated from the contribution of PBL moisture convergence due to the dynamics of free atmosphere and the $q^{\prime}$-induced $T^{\prime}$, while the net contribution of $T^{\prime}$ to $\Delta \theta_{e}{ }^{\prime}$ can be calculated from the contribution of $T^{\prime}$ change due to the surface heat and radiative fluxes and the $T^{\prime}$-induced $q^{\prime}$. For the P1-ISO (Fig. 11a), the net contribution of $q^{\prime}$ to $\Delta \theta_{e}{ }^{\prime}$ is negative, favoring the convection moving northward, while the net contribution of $T^{\prime}$ to $\Delta \theta_{e}{ }^{\prime}$ has a larger value, resulting in a positive total $\Delta \theta_{e}{ }^{\prime}$ that prevents the P1-ISO from propagating northward. For the P2-ISO (Fig. 11b), the contribution of $q^{\prime}$ to $\Delta \theta_{e}{ }^{\prime}$ is significantly decreased as excluding the effect from $T^{\prime}$-induced $q^{\prime}$, while the net contribution of $T^{\prime}$ to $\Delta \theta_{e}{ }^{\prime}$ is greatly increased. That implies that the change in $\Delta \theta_{e}{ }^{\prime}$ is mainly attributed to the $T^{\prime}$ change and the change in specific humidity over $\mathrm{SC}$ is greatly attributed to the $T^{\prime}$ for the P2-ISO, which is consistent with the conclusion from the partial correlation analysis.

\section{Summary and discussion}

The northward propagation of ISOs is evident over the SCS (Zheng et al. 2011; Zheng and Huang 2019), while just a little part can move from the SCS to SC as shown in Fig. 1. Why can some ISOs propagate from the SCS to SC and others not? That is an interesting and challenging issue we try to address preliminarily in this study.

To understand key processes of the northward-propagating ISOs from the SCS to SC, we divide the ISOs into P1-ISO with the northward propagation confined in the SCS (Fig. 3a) and P2-ISO that can move from the SCS to SC (Fig. 3b). Based on the NCEP-NCAR reanalysis, the structures and surface heat fluxes of these two ISOs are compared, and the lead-lag correlation and partial correlation analysis methods are used to further examine the relationship of various variables. According to the results, the change in convective instability over SC, mainly induced by the $q^{\prime}$ and $T^{\prime}$, is a key factor for the ISOs propagating from the SCS to SC.

For the P1-ISO, northward propagation is confined to the south of $21^{\circ} \mathrm{N}$ because of the convective instability decrement over SC that is mainly attributed to $T^{\prime}$. When the ISO center appears just in the south of the SCS a positive precipitation anomaly occurs over SC (Fig. 3a), and latter, although with a weak strength, should reduce the surface solar radiation (Figs. 6c and 8b) and then LST (Fig. 6b). Thereafter, as the P1-ISO move to the north of the SCS, the cold LSTAs (Fig. 6a) over SC cool the low-level air temperature in situ via decreased surface sensible heat flux (Fig. 6f) and longwave radiation (Fig. 6g). Thus the cold low-level air temperature reduces the convective instability over SC (Fig. 10) that prevents the P1-ISO from propagating northward. While the PBL moisture convergence, mainly controlled by the baroclinic vorticity advection (Bellon and Sobel 2008), appears slight north of the ISO center (Fig. 5a-c) and favors the ISOs moving northward, the total contribution from the convective instability changes is unfavorable for ISOs moving northward (Fig. 10). It implies that the change in low-level air temperature is a dominant factor for the P1-ISO confined in the SCS. Figure 12 shows the schematic diagram for the processes of P1-ISO that cannot propagate from the SCS to SC.

Different from the P1-ISO, the convective instability change over SC, for the P2-ISO, is mainly attributed to the $T^{\prime}$ and $T^{\prime}$-induced $q^{\prime}$. In the mechanism, the land surface heat flux plays an important role, which is consistent with the result from Webster (1983). As the ISO center appears in the SCS, a dry phase occurs over SC (Figs. $3 \mathrm{~b}$ and $8 \mathrm{e}$ ) 
Fig. 12 Schematic diagram for the processes of P1-ISO that cannot propagate from the SCS to SC. a As the ISO center is located south of the SCS, more precipitation over SC results in a less surface solar radiation, then a cooling at land surface. b When the ISO moves to the north of the SCS, the cold LST reduces the low-level air temperature by upward longwave radiation and sensible heat flux, thus stabilizing the troposphere. Although the effect of the baroclinic vorticity advection (Bellon and Sobel 2008) is an increase of the low-level moisture, then leading to an increase of the convective instability, the total $\Delta \theta_{e}{ }^{\prime}$ is a positive one that prevents the ISO from propagating northward

\section{P1-ISO}

(a)

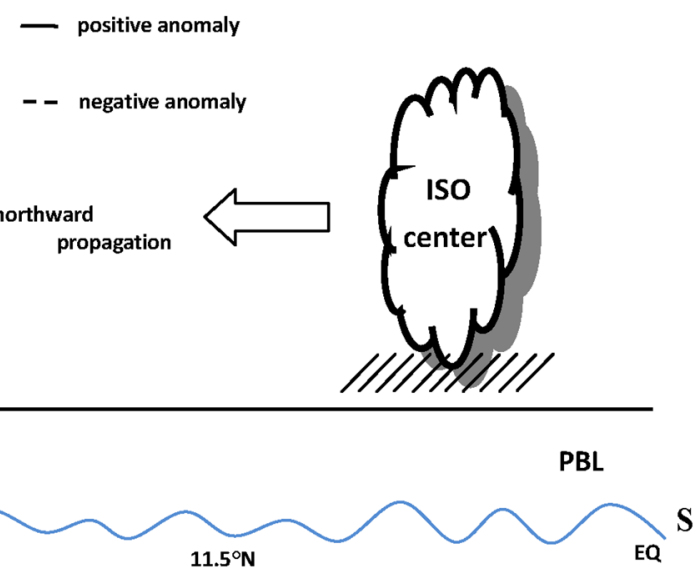

(b)

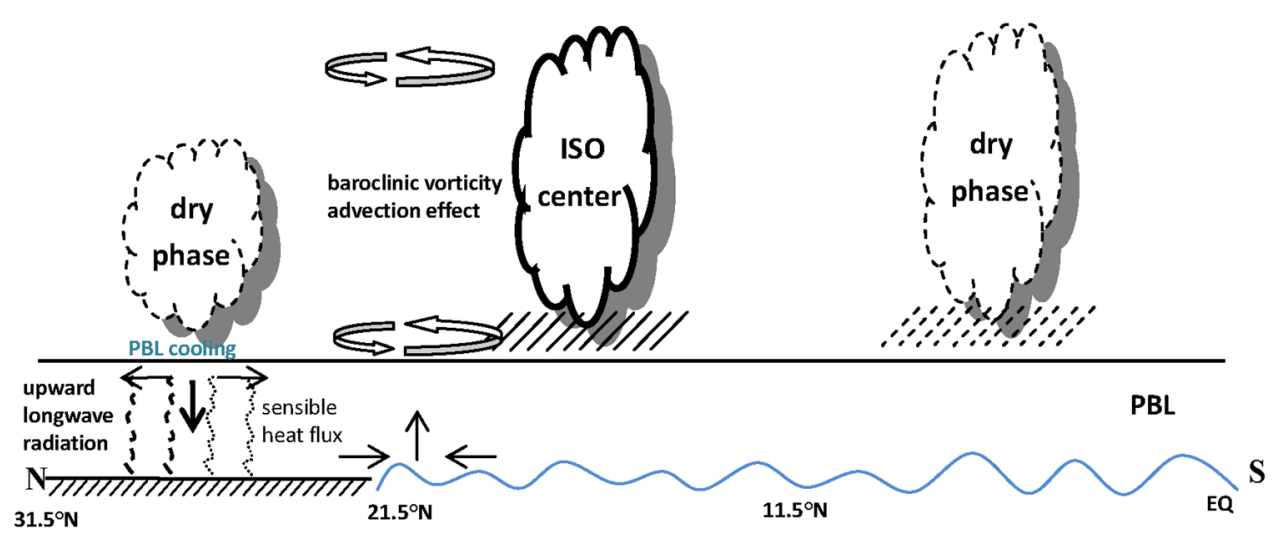

that leads to a more surface solar radiation (Figs. 7c and 8b) and then a warm LST (Fig. 7a and b). Thus the low-level air temperature is warmed to increase the convective instability over SC. In addition, $T^{\prime}$-induced $q^{\prime}$ is also important for the P2-ISO according to the partial correlation (Figs. 10 and $11 \mathrm{~b}$ ), whereas the moisture convergence, induced by the baroclinic vorticity advection (Bellon and Sobel 2008), is not an important role in modifying the convective instability (Figs. 10 and 11b). Figure 13 is the schematic diagram for the processes of P2-ISO that can move from the SCS to SC.

Webster (1983) pointed out that the land surface heat flux plays an important role in leading to a northward propagation of the ISOs, whereas the effects of radiative flux are ignored. In this study, we tend to conclude that the surface solar radiation and the longwave radiation are two main factors, aided by the sensible heat flux, in causing the northward propagation of ISOs from the SCS to SC. Moreover, the surface latent heat flux should be a key factor in the airsea interaction effect (Kemball-Cook and Wang 2001). However, the surface latent heat flux has a negative contribution to the northward propagation of ISOs from the SCS to SC via reducing the LST over SC (Fig. 7d). On the other hand, although the $\Delta \theta_{e}$ over SC is mainly attributed to the lowlevel $\theta_{e}$ for both the P1-ISO and P2-ISO (Fig. 9b), the midlevel tropospheric temperature (and moisture) may affect the convective instability change to some extent. While the midlevel $\theta_{e}$ change is controlled by the temperature anomaly, the former has negative contributions to the convective instability change in the P1-ISO and P2-ISO (Figure not shown). That is because, for the P1(P2)-ISO, the diabatic heating related to the latent heat release induced by precipitation induces a negative (positive) temperature anomaly during day -10 to day 0 (Fig. 3), and then the negative (positive) $\theta_{e}$ change at mid-level. Compared to low-level temperature anomaly, the mid-level one has an opposite and moderate contribution to the $\Delta \theta_{e}$ change (Figure not shown).

In this study, we also find that the baroclinic vorticity advection (Bellon and Sobel 2008) is not a key factor in driving the ISOs northward over SC. From Fig. 5d and e, we can see that the PBL convergence appears farther north than the barotropic vorticity for the P2-ISO. It implies that the $T^{\prime}$-induced convergence is more significant than that 
Fig. 13 Schematic diagram for the processes of P2-ISO that can propagate from the SCS to SC. a As the ISO center is located south of the SCS, less precipitation over SC leads to a more surface solar radiation, then warms the LST. b When the ISO moves to the north of the SCS, the positive LSTAs warm the low-level air temperature by upward longwave radiation and sensible heat flux, thus reducing the static stability over SC. Besides, the warm low-level air temperature could induce a PBL convergence and then lead to an increase of the specific humidity, which also strengthens the convective instability and tends to drive the ISO northward. Although the baroclinic vorticity advection (Bellon and Sobel 2008) would result in a convergence north of the convection center, the contribution to the convective instability is small
P2-ISO

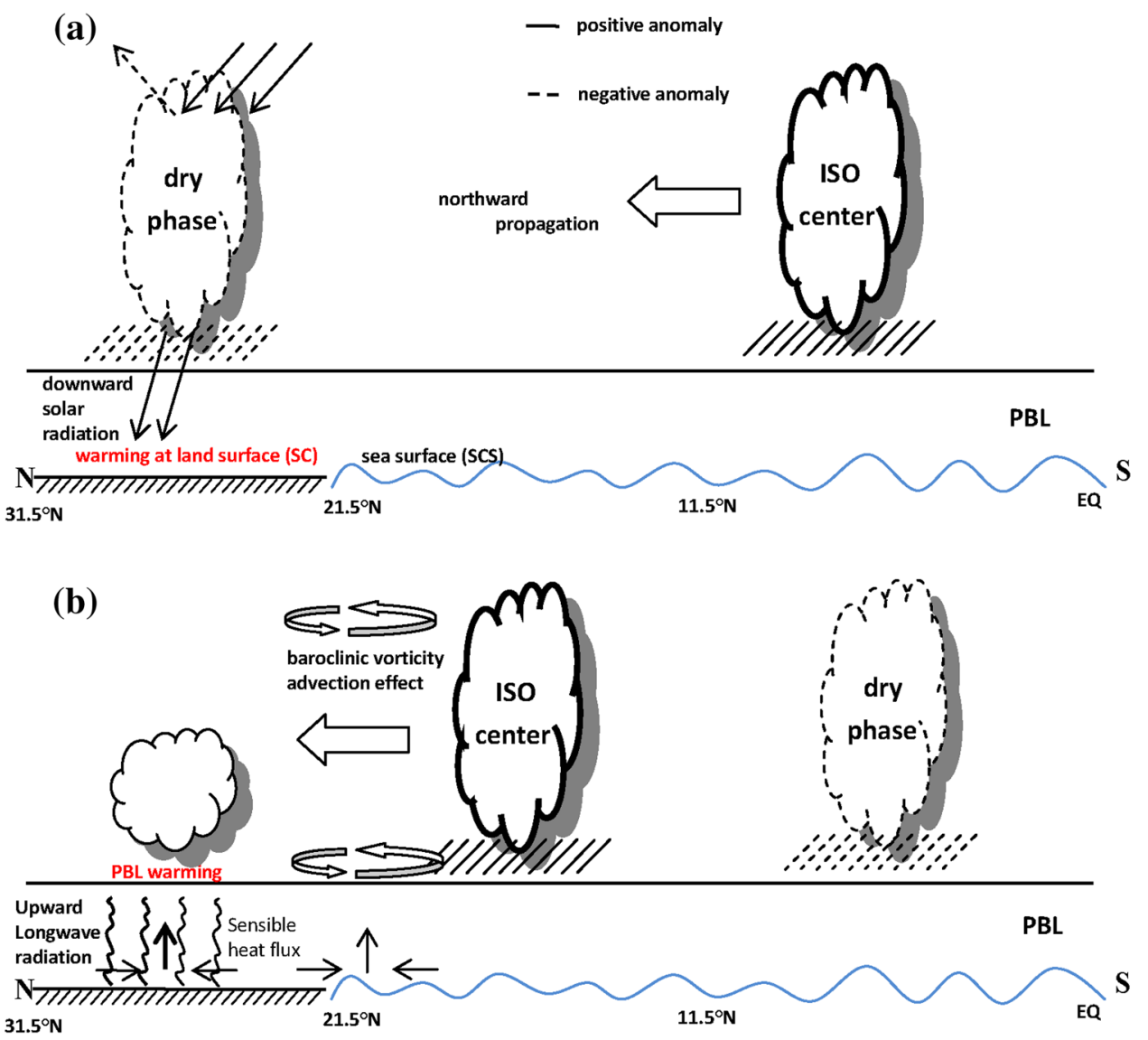

induced by the barotropic vorticity, which is consistent with the result from partial correlation analysis (Figs. 10 and 11b). While the barotropic vorticity shown in Fig. 5a has a similar pattern to the low-level convergence (Fig. 5b) for the P1-ISO, implying that the PBL convergence induced by the barotropic vorticity is more important relative to the $T^{\prime}$ -induced convergence. This and the result from partial analysis (Fig. 10) can be confirmed by each other.

More precipitation over SC is a key factor in slowing down the northward propagation of ISOs over the SCS. The occurrence time of enhanced rainfall is critical. As an ISO center just appears in the south of the SCS, more precipitation over SC should lead to stopping the northward propagation of ISO on the land-sea boundary. When the ISO propagates into the north of the SCS, enhanced rainfall over SC cannot prevent ISO from moving northward because of the response time as shown in Fig. 8a-d. Why does the enhanced precipitation over SC advance the ISO? It is pointed out in previous studies that persistent rainfalls in southern China should be influenced by both the tropical and subtropical systems (Zheng et al. 2007; Zheng and Huang 2018). There is no clear evidence showing the connection between the southward and northward propagations, while a persistent extreme precipitation would be triggered when they meet together (Hu et al. 2014; Zheng and Huang 2018). So the perturbation precipitation may originate, at least partially, from the southward propagation of ISO.

Acknowledgements This work is supported by the National Key R\&D Program of China (Grant No. 2018YFC1505801), National Natural Science Foundation of China (Grant Nos. 41705089, 41675096, and 41575043), and Science and Technology Program of Guangdong Province (Grant No. 2017B030314140). The NCEP-NCAR reanalysis data were obtained from ftp://ftp.cdc.noaa.gov/. The GPI data were obtained from https://ftp.cpc.ncep.noaa.gov/precip/gpi.

Open Access This article is licensed under a Creative Commons Attribution 4.0 International License, which permits use, sharing, adaptation, distribution and reproduction in any medium or format, as long as you give appropriate credit to the original author(s) and the source, provide a link to the Creative Commons licence, and indicate if changes were made. The images or other third party material in this article are included in the article's Creative Commons licence, unless indicated otherwise in a credit line to the material. If material is not included in the article's Creative Commons licence and your intended use is not permitted by statutory regulation or exceeds the permitted use, you will need to obtain permission directly from the copyright holder. To view a copy of this licence, visit http://creativecommons.org/licenses/by/4.0/. 


\section{References}

Bellon G, Sobel AH (2008) Instability of the axisymmetric monsoon flow and intraseasonal oscillation. J Geophys Res 113:D07108. https://doi.org/10.1029/2007JD009291

Boos WR, Kuang Z (2010) Mechanisms of poleward propagating, intraseasonal convective anomalies in cloud system-resolving models. J Atmos Sci 67:3673-3691. https://doi.org/10.1175/2010J AS3515.1

Chang C-P, Chen JM, Harr PA, Carr LE (1996) Northwestward-propagating wave patterns over the tropical western North Pacific during summer. Mon Wea Rev 124:2245-2266

Chen J, Wen Z, Wu R, Chen Z, Zhao P (2015) Influences of northward propagating 25-90-day and quasi-biweekly oscillations on eastern China summer rainfall. Clim Dyn 45(102):105-124. https://doi. org/10.1007/s00382-014-2334-y

DeMott CA, Stan C, Randall DA (2013) Northward propagation mechanisms of the boreal summer intraseasonal oscillation in the ERA-Interim and SP-CCSM. J Clim 26:1973-1992. https://doi. org/10.1175/JCLI-D-12-00191.1

Ding Y, He C (2006) The summer monsoon onset over the tropical eastern Indian Ocean: the earliest onset process of the Asian summer monsoon. Adv Atmos Sci 23(6):940-950

Drbohlav H-KL, Wang B (2005) Mechanism of the northward-propagating intraseasonal oscillation: Insights from a zonally symmetric model. J Clim 18:952-972

Gao J, Lin H, You L, Chen S (2016) Monitoring early-flood season intraseasonal oscillations and persistent heavy rainfall in South China. Clim Dyn 47:3845-3861. https://doi.org/10.1007/s0038 2-016-3045-3

Hsu P-C, Li T (2011) Interactions between boreal summer intraseasonal oscillations and synoptic-scale disturbances over the western North Pacific. Part II: apparent heat and moisture sources and eddy momentum transport. J Clim 24:942-961. https://doi. org/10.1175/2010JCLI3834.1

Hsu H-H, Weng C-H, Wu C-H (2004) Contrasting characteristics between the northward and eastward propagation of the intraseasonal oscillation during the boreal summer. J Clim 17:727-743

Hsu P-C, Li T, Tsou C-H (2011) Interactions between boreal summer intraseasonal oscillations and synoptic-scale disturbances over the western North Pacific. Part I: energetics diagnosis. J Clim 24:927-941. https://doi.org/10.1175/2010JCLI3833.1

Hsu P-C, Lee J-Y, Ha K-J (2016) Influence of boreal summer intraseasonal oscillation on rainfall extremes in southern China. Int $\mathrm{J}$ Climatol 36:1403-1412. https://doi.org/10.1002/joc.4433

Hsu P-C, Lee J-Y, Ha K-J, Tsou C-H (2017) Influences of boreal summer intraseasonal oscillation on heat waves in monsoon Asia. $\mathrm{J}$ Clim 30:7191-7211. https://doi.org/10.1175/JCLI-D-16-0505.1

Hu Y, Zhai P, Luo X, Lv J, Qin Z, Hao Q (2014) Large scale circulation and low frequency signal characteristics for the persistent extreme precipitation in the first rainy season over South China in 2013. Acta Meteorol Sin (in Chinese) 72(3):465-4770. https:// doi.org/10.11676/qxxb2015.042

Huffman GJ, Adler RF, Morrissey MM, Bolvin DT, Curtis S, Joyce R, McGavock B, Susskind J (2001) Global Precipitation at onedegree daily resolution from multisatellite observations. J Hydrometeor 2:36-50

Jiang X, Li T, Wang B (2004) Structures and mechanisms of the northward propagating boreal summer intraseasonal oscillation. J Clim 17:1022-1039

Kalnay E, Kanamitsu M, Kistler R, Collins W, Deaven D, Gandin L, Iredell M, Saha S, White G, Woollen J, Zhu Y, Leetmaa A, Reynolds B, Chelliah M, Ebisuzaki W, Higgins W, Janowiak J, Mo KC, Ropelewski C, Wang J, Jenne R, Joseph D (1996) The
NCEP/NCAR 40-year reanalysis project. Bull Am Meteorol Soc 77(3):437-472

Kang I-S, Kim D, Kug JS (2010) Mechanism for northward propagation of boreal summer intraseasonal oscillation: convective momentum transport. Geophys Res Lett 37:24804. https://doi. org/10.1029/2010GL045072

Kemball-Cook S, Wang B (2001) Equatorial waves and air-sea interaction in the boreal summer intraseasonal oscillation. J Clim 14:2923-2942

Krishnamurti TN, Subrahmanyam D (1982) The 30-50 day mode at 850mb during MONEX. J Atmos Sci 39:2088-2095

Li K, Yu W, Li T, Murty VSN, Khokiattiwong S, Adi TR, Budi S (2013) Structures and mechanisms of the first-branch northwardpropagating intraseasonal oscillation over the tropical Indian Ocean. Clim Dyn 40:1707-1720. https://doi.org/10.1007/s0038 2-012-1492-z

Li C, Li T, Gu D, Lin A, Zheng B (2015) Relationship between summer rainfall anomalies and sub-seasonal oscillations in South China. Clim Dyn 44:423-439. https://doi.org/10.1007/s0038 2-014-2172-y

Li C, Li T, Zheng B (2018) Characteristic interdecadal change of quasibiweekly and intraseasonal oscillations of summer convection over the South China Sea and the Western Pacific. Dyn Atmos Oceans 83:41-52. https://doi.org/10.1016/j.dynatmoce.2018.05.006

Lin A, Li T, Li C, Gu D, Zheng B, Luo J-J (2010) Relationship between interannual anomalies of sea surface temperature in the Indian Ocean and tropical boreal summer intraseasonal oscillations: observations and simulations. Acta Meteor Sin (in Chinese) 68(5):617-630

Liu F, Wang B, Kang I-S (2015) Roles of barotropic convective momentum transport in the intraseasonal oscillation. J Clim 28:4908-4920. https://doi.org/10.1175/JCLI-D-14-00575.1

Mao J, Chan JCL (2005) Intraseasonal variability of the South China Sea summer monsoon. J Clim 18:2388-2402

Murakami TN, He J (1984) On the 40-50 day oscillation during the 1979 Northern Hemisphere summer I: phase propagation. J Meteor Soc Jpn 62:440-468

Murakami T, Matsumoto J (1994) Summer monsoon over the Asian continent and western north Pacific. J Meteor Soc Jpn 72:719-745

Tsou C-H, Hsu P-C, Kau W-S, Hsu H-H (2005) Northward and northwestward propagation of 30-60 day oscillation in the tropical and extratropical western North Pacific. J Meteor Soc Jpn 83:711-726. https://doi.org/10.2151/jmsj.83.711

Wang B (1994) Climatic regimes of tropical convection and rainfall. J Clim 7:1109-1118

Wang B, Rui H (1990) Synoptic climatology of transient tropical intraseasonal convection anomalies: 1975-1985. Meteor Atmos Phys $44: 43-61$

Wang B, Xie X (1997) A model for the boreal summer intraseasonal oscillation. J Atmos Sci 54:72-86

Wang B, Huang F, Wu Z, Yang J, Fu X, Kikuchi K (2009) Multi-scale climate variability of the South China Sea monsoon: a review. Dyn Atmos Oceans 47:15-37. https://doi.org/10.1016/j.dynat moce. 2008.09.004

Webster PJ (1983) Mechanisms of monsoon low-frequency variability: surface hydrological effects. J Atmos Sci 40:2110-2124

Yasunari T (1979) Cloudiness fluctuations associated with the Northern Hemisphere summer monsoon. J Meteor Soc Jpn 57:227-242

Yasunari T (1980) A quasi-stationary appearance of 30- to 40-day period in the cloudiness fluctuations during the summer monsoon over India. J Meteor Soc Jpn 58:225-229

Zhang Z, Chan JCL, Ding Y (2004) Characteristics, evolution and mechanisms of the summer monsoon onset over Southeast Asia. Int J Climatol 24:1461-1482. https://doi.org/10.1002/joc.1082 
Zhao C, Li T, Zhou T (2013) Precursor signals and processes associated with MJO initiation over the tropical Indian Ocean. J Clim 26:291-307. https://doi.org/10.1175/JCLI-D-12-00113.1

Zheng B, Huang Y (2018) Mechanisms of meridional-propagating high-frequency intraseasonal oscillation associated with a persistent rainfall over South China. Mon Wea Rev 146:1475-1494. https://doi.org/10.1175/MWR-D-17-0260.1

Zheng B, Huang Y (2019) Mechanisms of northward-propagating intraseasonal oscillation over the South China Sea during the pre-monsoon period. J Clim 32(11):3297-3311. https://doi. org/10.1175/JCLI-D-18-0391.1

Zheng B, Lin A, Yuan J, Gu D, Li C, Liang J (2007) Study on the cause of Heavy Rain 200506 (HR0506) in Guangdong. J Trop Meteor 13(2): 145-148

Zheng B, Lin A, Li C, Gu D (2011) The northward propagation and mechanisms of the intraseasonal oscillation of South China Sea summer monsoon in 2007. J Trop Meteor (in Chinese) 27(6):869 876. https://doi.org/10.3969/j.issn.1004-4965.2011.06.010
Zheng B, Lu F, Wei H (2013) Air-sea interactions associated with tropospheric biennial oscillation in South China Sea summer monsoon and their effects on El Niño-Southern Oscillation. Acta Oceanol Sin 32(6):6-12. https://doi.org/10.1007/s13131-013-0319-Z

Zheng B, Huang Y, Li C (2019) The 30-60-day northward-propagating intraseasonal oscillation over South China Sea during premonsoon period in a coupled model. Int J Climatol. https://doi. org/10.1002/joc.6109

Zhou C, Li T (2010) Upscale feedback of tropical synoptic variability to intraseasonal oscillations through the nonlinear rectification of the surface latent heat flux. J Clim 23:5738-5754. https://doi. org/10.1175/2010JCLI3468.1

Publisher's Note Springer Nature remains neutral with regard to jurisdictional claims in published maps and institutional affiliations. 